http://dx.doi.org/10.35381/racji.v5i1.612

\title{
Derecho al proceso en el cometimiento de infracciones administrativas por propietarios de locales comerciales
}

Right to process in committing administrative infractions by business premises owners

\author{
Carlos Bayardo Cañarte-Sisalima \\ carlos.canarte@psg.ucacue.edu.ec \\ Universidad Católica de Cuenca, Cuenca \\ Ecuador \\ https://orcid.org/0000-0001-8121-3371 \\ Juan Carlos Erazo-Álvarez \\ jcerazo@ucacue.edu.ec \\ Universidad Católica de Cuenca, Cuenca \\ Ecuador \\ https://orcid.org/0000-0001-6480-2270 \\ José Luis Vázquez-Calle \\ jivazquezc@ucacue.edu.ec \\ Universidad Católica de Cuenca, Cuenca \\ Ecuador \\ https://orcid.org/0000-0003-4980-6403 \\ Cecilia Ivonne Narváez-Zurita \\ inarvaez@ucacue.edu.ec \\ Universidad Católica de Cuenca, Cuenca \\ Ecuador \\ https://orcid.org/0000-0002-7437-9880
}

Recibido: 14 de noviembre de 2019

Aprobado: 15 de diciembre de 2019

\section{RESUMEN:}

El presente estudio aborda desde un punto de vista Constitucional la eficacia y validez que tiene el Acuerdo Ministerial 0069 en cuanto al procedimiento de clausura de los centros y establecimientos que dicho acuerdo enlista. El problema a analizar es la 
forma de clausura y la colocación de sellos a estos centros o establecimientos por infracciones administrativas. La metodología fue el método analítico, con la finalidad de analizar normas y principios jurídicos que se encuentren afectados con el problema; el método deductivo para realizar la descomposición teórica del problema; el método inductivo, se recurre a este para partir de lo particular evidenciando el problema procesal y al sector que afecta. Entre los resultados del presente estudio además de criterios de selectos tratadistas del derecho, se llegó al convencimiento de elaborar un procedimiento de clausura y colocación de sellos a los centros y establecimientos mencionados.

Descriptores: Debido proceso, seguridad jurídica, derecho a la defensa, clausura, Acuerdo Ministerial 0069.

\begin{abstract}
The present study addresses from a Constitutional point of view the effectiveness and validity of the Ministerial Agreement 0069 regarding the closing procedure of the centers and establishments that said agreement lists. The problem to analyze is the form of closure and the placement of stamps to these centers or establishments for administrative infractions. The methodology was the analytical method, in order to analyze legal norms and principles that are affected by the problem; the deductive method to perform the theoretical decomposition of the problem; the inductive method, this is used to start from the particular evidence of the procedural problem and the sector it affects. Among the results of the present study, in addition to the criteria of select legal practitioners, the conviction was reached to prepare a closing and stamp procedure for the centers and establishments mentioned.
\end{abstract}

Descriptors: Due process, legal certainty, right to defense, closure, Ministerial Agreement 0069.

\title{
INTRODUCCIÓN
}

El Derecho Constitucional, rama del derecho público es dedicado a los aspectos esenciales de la organización, modo operativo del poder del Estado, al reconocimiento de los derechos fundamentales y al establecimiento de garantías; en breves palabras es la base de todo el ordenamiento jurídico de donde como ramificaciones nacen las normativas secundarias. Como fruto del poder Constituyente, la Constitución; tiene el 
carácter de norma suprema, es superior a cualquier otra posterior o contraria a ella. Contempla todo un cuerpo de texto solemne en cual organiza al poder del Estado y en el que establece todo un régimen de garantías y principios fundamentales; regulados estos aspectos en su parte orgánica y dogmática, situándose en la parte dogmática los principios de la institucionalidad del Estado.

Con estos breves antecedentes, cuando se habla de Seguridad Jurídica se refiere a un principio que nace y es emitido por el Estado hacia los individuos, en el que se garantiza que su persona, bienes y derechos no serán violentados; y que si esto llegara a ocurrir se asegura una reparación por aquellos. De igual manera el debido proceso es una garantía que tiene una naturaleza amplia y estricta que circunscribe a la eficiencia procesal del modo de administrar justicia, además de referirse a la interpretación de la ley y a los aspectos axiológicos y teológicos del derecho. Estas dos garantías son de aplicación universal y sin ellas no hay derecho que valga, aquí radica su importancia.

La Constitución de la República del Ecuador, reconoce las diferentes formas de producción en la economía y garantiza que el Estado velará por promover las formas de producción que aseguren el buen vivir de la población y desincentivará aquellas que atenten contra sus derechos, uno de los sectores productivos es que conforman los propietarios de centros o establecimientos categorizados en: centros de tolerancia, centros de diversión para mayores de 18 años, licorerías y depósitos de bebidas alcohólicas al por mayor, locales de consumo de alimentos preparados, tiendas y abacerías, centros de entretenimiento, hospedaje; se encuentran sujetos al Acuerdo Ministerial 0069, que de manera similar los Intendentes Generales de Policía, las y los Subintendentes de Policía y Comisarios Nacionales de Policía a nivel nacional son materia de dicho acuerdo donde se regula las atribuciones de las autoridades públicas mencionas, los permisos de funcionamiento, las infracciones administrativas, las sanciones administrativas entre otros aspectos relacionados a los espectáculos públicos. 
La situación actual de la actividad económica de los propietarios de los centros o establecimientos mencionados es un tema preocupante y poco analizado; frente a la forma de proceder y resolver sobre el cometimiento de infracciones administrativas, dejando espacio para resaltar una vulneración de derechos y garantías constitucionales. Dicho Acuerdo Ministerial expedido recientemente nos lleva a mantener un proceso ambiguo de clausura de los centros o establecimientos enmarcados en las siete categorías establecidas, dado que, este procedimiento no ha sufrido ningún cambio con el devenir de los años, con el desarrollo social, con la evolución del derecho y que además mantiene discrepancias con la Constitución de la República.

Concretamente, es de referirse a la forma de clausura y a la colocación de sellos a estos centros o establecimientos por infracciones administrativas; tarea que la realizan los Intendentes Generales de Policía, las y los Subintendentes de Policía y Comisarios Nacionales de Policía a pesar que dentro de sus atribuciones y responsabilidades no figura expresamente dicha acción, pero más allá de ello, es de considerar si es o no una forma correcta de llevar el proceso administrativo por infracciones de la misma índole. Estas clausuras efectuadas en los operativos de control, se ubican los sellos como una medida cautelar y emiten un auto de apertura del procedimiento, con ello, se fija el término de diez días para el ejercicio de la defensa del supuesto infractor y se sigue un procedimiento que lleva hasta una resolución donde, para el levantamiento de los sellos de clausura; independientemente si se determina o no la infracción el propietario o representante legal del centro o establecimiento debe cubrir un valor, que es establecido por concepto de recuperación de costos administrativos con un plazo de tres meses, que termina representado un perjuicio económico al propietario.

Estas deficiencias del acuerdo ministerial transgreden principios del derecho universales y que se encuentran reconocidos en nuestra carta magna. ¿Se puede optar por una aplicación del debido proceso más adecuado al momento de ejecutar el Acuerdo Ministerial 0069 para no vulnerar derechos de los propietarios de los centros 0 
establecimientos comerciales y encaminarse a una correcta administración de justicia más efectiva en estos actos de infracciones administrativas?

A esta interrogante se pretende dar estudio, evidenciar la repercusión económica que transciende a las familias y negocios indirectos dependientes de los ingresos de estas actividades económicas; además busca dar respuesta a la interrogante planteada en el presente trabajo académico, encaminado a exponer una perspectiva desarrollada bajo fundamentos teóricos y, más a fin al debido proceso, a la seguridad jurídica y al derecho de defensa; con el objetivo de precautelar los derechos de los propietarios 0 representantes de los centros o establecimientos comerciales en las categorías señaladas. La presente investigación se centra en analizar el debido proceso.

Bajo estas condiciones se infiere como problema ¿Cómo garantizar el debido proceso del procedimiento de la clausura de los establecimientos del acuerdo ministerial 0069?, el objetivo es proponer un procedimiento basado en los derechos constitucionales de la seguridad jurídica y derecho a la defensa que asegure el debido proceso del procedimiento de la clausura de los establecimientos del acuerdo ministerial 0069

\section{DESARROLLO}

\section{Generalidades de los actos administrativos en función a la seguridad jurídica.}

Es necesario recurrir a la mención y a un breve análisis de los conceptos básicos para ir hilando con el tema y objetivo principal planteados, por ello se debe partir desde el acto administrativo y desde donde es emanado. Entonces el acto administrativo se lo puede definir como un acto jurídico especial y un medio por el cual, la administración pública lo utiliza para manifestar su voluntad y que a la vez produzca efectos jurídicos. Este tipo actos emanados de la administración, imponen su cumplimiento e intervención jurisdiccional que se pueda ocasionar, por el mismo hecho de tener un carácter unilateral donde se crea, reconoce, modifica o extingue situaciones jurídicas subjetivas. Ahora bien, es de señalar a las infracciones administrativas como ciertas acciones $u$ omisiones a las cuales les corresponde una sanción del mismo carácter administrativo. 
Cordero (2012) considera que las infracciones administrativas se caracterizan por "la gravedad de la sanción, la posibilidad de aplicarlas sin mayores restricciones a las personas jurídicas, la configuración de injustos administrativos cuya valoración éticasocial es menor que las contenidas en los delitos" (p. 140). Con el aporte de este jurista mencionado se puede determinar el carácter transgresor que tienen las infracciones administrativas, y como se menciona, no se excluyen de las mismas a las personas jurídicas, además de ello se despeja el punto de relación con el derecho penal al considerar que una infracción administrativa es mucho menor que un delito.

A cada infracción administrativa le corresponde una sanción administrativa, en los artículos que hace referencia clasifica estas infracciones en leves, graves y muy graves, asignándoles sanciones proporcionales en medida de la infracción y una multa de acuerdo a la categoría del centro o establecimiento y su actividad económica catalogados en el mismo acuerdo en siete categorías que son: centros de tolerancia, centros de diversión para mayores de 18 años, licorerías y depósitos de bebidas alcohólicas al por mayor, locales de consumo de alimentos preparados, tiendas y abacerías, centros de entretenimiento, hospedaje.

Como es recíproco a cada infracción conlleva su respectiva sanción, las coerciones que este Acuerdo Ministerial demanda son la suspensión de la actividad económica, la clausura del establecimiento desde 10 hasta 30 días y por reincidencia de faltas, por ser cómplices o autores de delitos dentro del interior de su establecimiento o por otras acciones de mayor gravedad la clausura definitiva y revocatoria del permiso anual de funcionamiento. Además de ello, es de considerar como una sanción adicional a las enunciadas, el pago por recuperación de la especie valorada que es el sello de clausura, con un costo de cien dólares americanos.

Ahora bien, en los procedimientos actuales por faltas sean leves, graves o muy graves los propietarios o representantes de los centros y establecimientos que cataloga el Acuerdo Ministerial 0069, primero se coloca los sellos de clausura en lo que se conoce por motivos de flagrancia, como una medida cautelar. Luego de esto se emite el auto de 
apertura dictado por el órgano instructor de la jurisdicción que corresponda; con ello se pasa a desarrollar todo el proceso estableciendo días término para el ejercicio de la defensa del propietario considerado supuesto infractor. Acto seguido se da una notificación del acto de iniciación por el órgano instructor, se desarrollan las actuaciones de instrucción, la carga de pruebas y el dictamen.

Retomando a la clausura de los centros y establecimientos de las siete categorías, aquí es donde radica un problema relevante en las medias cautelares, que dichas medidas terminan siendo una sanción emitida de manera anticipada e independientemente de una resolución dado que, si el supuesto infractor en el ejercicio de su defensa resulta no ser infractor, debe pagar para el levantamiento de los sellos de clausura. En estos casos la sanción es impuesta incluso previa tramitación de un expediente administrativo, que no necesariamente puede resultar con un carácter sancionador, dado que el expediente está destinado a verificar los supuestos de la infracción administrativa lo que además nos conduce a un prejuzgamiento del supuesto infractor.

Ahora bien, textualmente respecto del levantamiento del sello de clausura al Acuerdo Ministerial ya mencionado en su artículo 44 incisos 3 y 4 señala:

El incumplimiento del pago del valor establecido por este concepto, conllevará a la negativa para la obtención del Permiso Anual de Funcionamiento que sea requerido por la o el propietario, administrador o representante legal con respecto el establecimiento sancionado. Esta restricción se mantendrá hasta que se proceda con el pago total del valor pendiente. El valor por concepto de recuperación de costos administrativos generado a consecuencia de las sanciones impuestas, será aquel que la máxima autoridad a través de acto administrativo, haya establecido con base a la normativa que rige la planificación y finanzas públicas.

A Criterio personal no es conveniente este procedimiento, el propietario es afectado en el ejercicio de su actividad económica, además que en la realidad social los propietarios y administradores de estos centros y establecimientos, acuden a estos procedimientos sin un abogado defensor, allanándose a la infracción con el objetivo de que se les asigne una sanción mínima; con ello es muy poco probable que de estos 
procedimientos se determine que no hay infracción. Es de destacar nuevamente que el pago del levantamiento de los sellos es ya una sanción y que una sanción no debe ser impuesta sin un trámite o proceso anterior acorde a todas las garantías y derechos constitucionales. "Para la imposición de sanciones por infracciones administrativas en el orden social será obligatoria la previa tramitación del oportuno expediente, en la que habría que respetarse las garantías y observarse los requisitos establecidos" (Moreno, 2012, p. 36).

Dentro de este régimen administrativo para las infracciones de carácter administrativas, otro aspecto a mencionar es que, dentro de las atribuciones de los Intendentes Generales de Policía, las y los Subintendentes de Policía y Comisarios Nacionales de Policía contenidas en los artículos 4, 5 y 6 del Acuerdo Ministerial 0069, expresamente no indica que estas entidades están facultadas para realizar dichas clausuras a los centros y establecimientos de las siete categorías que el mismo Acuerdo Ministerial contiene. Si bien en el Código Orgánico Administrativo en el artículo 189 establece que el órgano competente, cuando la ley lo permita, de oficio o a petición de la persona interesada, podrá ordenar medidas cautelares incluidas entre estas la clausura de los establecimientos.

Es un requerimiento fundamental que tanto el Acuerdo Ministerial citado con el Código Orgánico Administrativo tengan una uniformidad en sus cuerpos orgánicos, dado que esto facilita tanto al proceso como a la defensa y a la misma autoridad administradora de justicia para la aplicación de las mismas normas (Granda Torres \& Herrera Abrahan, 2019). Con todo este breve análisis de conceptos fundamentales del régimen administrativo para las infracciones administrativas, se ha desarrollado un núcleo importante de la investigación donde se evidencia que existe una problemática que afecta a derechos y garantías constitucionales. 


\section{El debido proceso en la aplicación del Acuerdo Ministerial 0069 respecto a las funciones, atribuciones y responsabilidades de los Intendentes y Comisarios de Policía del Ecuador.}

Es oportuno continuar el desarrollo del presente estudio en la relación con el debido proceso, la seguridad jurídica y el derecho a la defensa como los núcleos que configuran este estudio. ¿Qué es el debido proceso? ¿Cómo funciona en nuestro sistema jurídico? ¿Cómo se debe concebirlo en forma apropiada? y aún más relevante ¿cómo se relaciona el debido proceso con el acuerdo Ministerial 0069?

El debido proceso rige en todos los países de Occidente y en los países civilizados de Oriente, es denominado como el Due Process of Law en Estados Unidos procedente del derecho anglosajón. En sí es un derecho y principio Constitucional y de carácter universal que tiene por objeto proteger derechos de las arbitrariedades que pueden surgir en los procedimientos formales y que se encuentran previamente establecidos en los cuerpos legales susceptibles, de ser aplicados y dirigidos por autoridades con un criterio imparcial.

De las definiciones de algunos destacados autores es relevante citar que es concebido como una "Garantía Constitucional consistente en asegurar a los individuos la necesidad de ser escuchados en el proceso en que se juzga su conducta, con razonables oportunidades para la exposición y prueba de sus derechos" (Couture, 1978, p. 199). El jurista citado se posiciona en la perspectiva de considerar al debido proceso como una garantía y no como un derecho, y concreta que su objeto es particular dado que radica en el sujeto y que este "sea escuchado en el proceso" y en "las oportunidades para la exposición y prueba de sus derechos". A criterio personal el debido proceso tiene dos formas de actuar a la primera como lo señala el autor mencionado en forma particular, y la segunda en una forma universal al tener la misión de proteger a los individuos y a la correcta aplicación de todo el sistema normativo vigente. 
Otro de las definiciones que consideran al debido proceso como una garantía es la del jurista Frankfurter citado por Cowin, en donde se deduce que "El debido proceso de ley es una garantía Constitucional resumida de respeto a esas inmunidades personales que están tan arraigadas en las tradiciones y la conciencia de nuestro pueblo que puede considerarse las fundamentales o que están implícitas en el concepto de libertad sujeta a un orden" (1987 p.505 y 506). Interpretando la cita nos lleva a la percepción de que el debido proceso, es violado cuando un procedimiento agrede a la conciencia, y que esta garantía que manifiesta el autor citado se configura, en el respeto de la persona y su libertad enmarcado todo en un ordenamiento social y jurídico. Por último para apreciar lo que es el debido proceso y tener una alumbrada definición, es relevante citar la que postula el profesor Zavala que al respecto señala:

Entendemos por debido proceso el que se inicia, se desarrolla y, concluye respetando y haciendo efectivos los presupuestos; los principios y las normas constitucionales legales e internacionales aprobadas previamente, así como los principios generales que informan el derecho procesal penal, con la finalidad de alcanzar una justa administración de Justicia, provocando como efecto inmediato la protección integral de la seguridad jurídica del ciudadano, reconocida constitucionalmente como un derecho (2002, p. 25).

Con esta percepción del debido proceso, se resalta la forma en que actúa en todo el sistema jurídico, para evitar una afectación o vulneración de derechos a los ciudadanos por parte de los órganos del poder público; debiendo ser un principio observado, garantizado y practicado en todos los procesos judiciales, legislativos, administrativos, electorales, entre otros para la resolución de conflictos en persecución de una correcta administración de Justicia.

Ya con las breves especificaciones del debido proceso, es necesario encaminarnos a preguntar: ¿Se puede violar el debido proceso? ¿En qué circunstancias se lo viola? ¿Quiénes violan el debido proceso? El debido proceso comúnmente es afectado por la falta de conocimiento, por malas diligencias judiciales, por una interpretación errónea de la normativa; puede ser la situación que sea por mala fe o por una falta de 
imparcialidad, por colocar a un individuo en estado de indefensión, por rechazar arbitrariamente un recurso, entre otras razones o situaciones posibles.

El debido proceso es un derecho constitucional, por lo tanto, es de rango superior e impregna todo el sistema jurídico de un país: nadie puede ignorarlo. Todos los actos y procedimientos de los funcionarios de los órganos del poder público deben ceñirse a él, de lo contrario, atentaría contra el Estado de Derecho y carecería de validez jurídica. (Cueva, 2015, p. 79).

En lo esencial, Cueva (2013) enlista de manera muy concreta los casos que señala la Corte Nacional Justicia y la Corte Constitucional; donde se ha violado el debido proceso entre ellos el caso que se relaciona con el tema principal que es "cuando se juzga a un sujeto sin oírlo" y "cuando no se le permite hacer uso del derecho de defensa". Es de decir entonces, se viola el debido proceso cuando se emite una medida cautelar, que más que medida es parte de una sanción impuesta anticipadamente, sin un juzgamiento y sin un procedimiento previo, es decir que se ha juzgado a el sujeto; en el caso del tema de estudio a los propietarios o administradores de los centros de las siete categorías que enlista el Acuerdo Ministerial 0069; sin este haber sido escuchado o ejercido un derecho a la defensa, previo a esa sanción prematura.

Al estar la autoridad Administrativa como lo son los Intendentes Generales de Policía, las y los Subintendentes de Policía y Comisarios Nacionales de Policía sujetos a la observancia del debido proceso, se incurre en una violación al mismo al colocar estos sellos de clausura en los establecimientos mencionados, con ello afecta aspectos de derechos, aspectos jurídicos y en adición a esto se produce una afectación económica importante en los propietarios y administradores de los establecimientos en cuestión.

Como datos estadísticos es importante traer a mención que el INEC en una encuesta realizada en el año 2015 , señala que el $21 \%$ de la población ecuatoriana se dedica a trabajos en hoteles y restaurantes, estos conforman solo dos categorías de las siete que señala el Acuerdo Ministerial 0069. Estos dos tipos de establecimientos dinamizan económicamente el otro $79 \%$ restante de la población que desempeña una actividad 
económica, debido a que ocupa o gasta en los servicios que este otro porcentaje ofrece.

Además de ello, es de considera que cada establecimiento o centro que el Acuerdo Ministerial 0069 cataloga en su artículo 10; requieren de cuatro a diez personas y en algunos de mayor necesidad más de diez personas para laborar en dichos establecimientos. Lo que una clausura sin un procedimiento previo, al menos por faltas leves significa un perjuicio económico muy significativo, dejando a varias personas sin una actividad laboral y por ende una remuneración por varios días, hasta que se dictamine el cometimiento de la infracción administrativa.

En el sistema jurídico de nuestro país el debido proceso es quién vigila que todo juzgamiento sea según el procedimiento adecuado y legalmente correspondiente, que se cumpla cada etapa de una manera apegada a la Constitución de la República y a la legalidad. El Estado por su parte además debe asumir la responsabilidad que señala el artículo 11 numeral 9, inciso cuarto de la Constitución "(...) por las violaciones de los principios y reglas del debido proceso".

La normativa fundamental del debido proceso establecida en la Constitución es la que indica los artículos 75 y 76 . Las partes de esta normativa que se pueden considerar como vulneradas en el tema propuesto y por ende el cometimiento de una violación al debido proceso son los incisos 2, y 7 del artículo 76 ya mencionado que radica en determinar todas las garantías al debido proceso, de las cuales es de mencionar que "Se presumirá la inocencia de toda persona, y será tratada como tal, mientras no se declare su responsabilidad mediante resolución firme o sentencia ejecutoriada" y " el derecho de las personas a la defensa (...)".

El primer inciso se vulnera en la colocación de los sellos de clausura previo al procedimiento dado que a criterio propio, la colocación de estos sellos ya consiste en una sanción anticipada sin existir una resolución en firme debido que si se determina o no la infracción administrativa el valor de los sellos de clausura debe ser pagado, por ello no existiría la garantía de presumir la inocencia del propietario o administrador de 
los centros o establecimientos mencionados, se lo está ya considerando como un infractor y está siendo tratado como tal al estar suspendido de ejercer su actividad económica con esa clausura.

En cuanto al otro inciso mencionado es de considerar que el derecho a la defensa es también violentado al no existir un procedimiento previo y ya en la realidad si bien en el procedimiento que señala el Acuerdo Ministerial 0069 en su artículo 34 inciso 6 donde se le otorga al presunto infractor un término de 10 días para ejerza su defensa; pero la mayoría de los propietarios y administrativos de estos establecimientos, comparecen sin un abogado defensor y decididos a someterse a un allanamiento de la infracción con la finalidad de obtener una sanción menor por la necesidad urgente de volver a retomar la actividad económica que venía realizando previo a la clausura. Respecto al derecho a la defensa es un tema en lo cual hay muchos más aspectos importantes por señalar por cuanto, se lo tratará de forma más detenida posteriormente en el presente estudio. El debido proceso está desarrollado en la legislación ecuatoriana en una forma muy pormenorizada para la práctica como consta en el artículo 3 del Código Orgánico de la Función Judicial que con "el fin de garantizar el acceso a la justicia el debido proceso, la independencia judicial y los más principios establecidos en la Constitución y este Código", en este mismo Código también se dispone que los jueces son responsables de que se "hagan efectivas las garantías del debido proceso". Con esto queda respaldado jurídicamente que se debe cuidar que se respeten los derechos y garantías de las partes procesales y las normas del debido proceso. El debido proceso de aplicación universal ningún proceso no debe prescindir de él.

El debido proceso es también reconocido en el Derecho Internacional figura en los artículos 7, 8 y 25 de la Convención Americana sobre Derechos Humanos donde como principios del debido proceso, se refieren al derecho a la libertad personal, a las garantías Judiciales y a la protección judicial. También se lo puede situar dentro del pacto Internacional de Derechos Civiles y Políticos en cuyo artículo 14 contiene las 
normas del debido proceso, con estas referencias se afirma la universalidad del debido proceso y la aplicación del mismo en nuestra legislación.

Se puede determinar que es posible establecer un procedimiento más acorde al debido proceso, para la aplicación del acuerdo Ministerial 0069 en relación a las infracciones administrativas de los centros y establecimientos que él mismo lo clasifica, en donde la colocación de los sellos de clausura a estos establecimientos sea después de un procedimiento y de una sentencia en firme con carácter sancionador. Así mismo para una mejor aplicación de este acuerdo que mantenga una uniformidad con respecto a las atribuciones que el Código orgánico administrativo señala para los Intendentes Generales de Policía, las y los Subintendentes de Policía y Comisarios Nacionales de Policía dado que la atribución de clausurar estos locales mencionados no figura de manera expresa dentro las responsabilidades de estos en el Acuerdo Ministerial 0069; la uniformidad de los cuerpos legales encamina toda la aplicación de las mismas a una correcta administración de Justicia, más ágil y efectiva.

\section{Afectación a la Seguridad Jurídica en el procedimiento para clausura de establecimientos.}

En cuanto al siguiente núcleo necesario a tratar en el desarrollo del presente estudio es la seguridad jurídica, resulta ser este un tema complejo bajo cualquier enfoque y de difícil análisis. Gometz, traducido por Moreno señala que "Se considera a la seguridad jurídica como valor fundamental del ordenamiento $y$, por tanto, como principio normativo y orientador del mismo" (2012, p. 43). A definición propia la seguridad jurídica es un derecho universalmente reconocido; que se refiere a la certeza que tienen los ciudadanos o los gobernados de un país a cerca de su familia, bienes, derechos de encontrarse bajo una protección por las diferentes leyes existentes e incluso se garantiza que sí sé es parte de un proceso legal o administrativo, este va a realizar según lo establecido en el marco jurídico vigente. 
Para esclarecer el rol de la seguridad jurídica, es oportuno recurrir a una sentencia de 29 de abril del 2010, resolución No. 16- SEP-CC, en los casos Nos. 0092-09-EP Y No. 0519-09-EP, acumulado sobre la seguridad jurídica entre varias expresiones dice:

La seguridad jurídica, es un conjunto de condiciones, de medios y de procedimientos jurídicos eficaces, que permiten desarrollar la personalidad de los ciudadanos en el ejercicio de sus derechos sin miedos, incertidumbre, amenaza, daños o riesgos, lo cual crea un ambiente de previsibilidad, no solo sobre el comportamiento ajeno, sino del comportamiento propio, y provocadas no solo por el Estado sino también por particulares.

Con esta afirmación, seguridad jurídica se puede exponer que, es la aspiración suprema de la justicia la cual se levanta sobre la base de las normas y principios del debido proceso su alcance y contenido, todo esto en amparo del respeto de los derechos constitucionales. Por otra parte, en la sentencia 08 de octubre de 2009, la No. 028-09-SEP-CC, caso No. 0481-08-EP, sobre la seguridad jurídica, en resumen, dice:

Es la necesidad de certeza y seguridad jurídica, uno de los principios que alimentan el núcleo duro del deber ser de las formalidades y solemnidades que caracterizan a los procesos en derechos, sin embargo, la seguridad jurídica no se agota en las meras formas, pues en muchos casos dichas formalidades y solemnidades podrían ser el mecanismo de perpetuación de una injusticia o un sin razón jurídico. De esta manera, la seguridad jurídica es uno de los resultados de la certeza que otorga el cumplimiento de las formalidades jurídicas en el tiempo y a lo largo del proceso.

El Estado Ecuatoriano garantiza la seguridad jurídica en su artículo 82 de la Constitución de la República donde la reconoce como un derecho y de manera expresa dice lo siguiente "se fundamenta en el respeto a la Constitución y en la existencia de normas jurídicas previas, claras públicas y aplicadas por las autoridades competentes". Por cuanto un mejor procedimiento para la aplicación del acuerdo Ministerial 0069 contribuiría al fortalecimiento de la seguridad jurídica en el Ecuador, por cuanto asegurando que estos propietarios de los centros y establecimientos de las siete categorías del ya enunciado acuerdo Ministerial se les otorgaría mayor seguridad para ejercer sus actividades económicas con libertad y estabilidad de operar siempre y 
cuando se mantenga en un fiel apego al no cometimiento de ningún tipo de infracciones y de ser el que caso que se someterán a un procedimiento administrativo acorde a su infracción.

Es de considerar que en la realidad actual estos propietarios corren el riesgo de que su local o establecimiento quiebre o deba cerrar definitivamente, considerando que una clausura previa a un procedimiento, más el costo de los levantamientos de los sellos de clausura representa una afectación de gran significado al propietario de estos centros, este sector poblacional que ejerce este tipo de actividades que norma el Acuerdo Ministerial 0069 no tienen una seguridad de que sus bienes, derechos no serán afectado e incluso su familia, considerando que de estas actividades económicas se provee recursos a hogares. Se afianza esta percepción con lo que se señala en la Sentencia del pleno de la Corte Constitucional No. 0368-2009-RA, publicada en el Registro Oficial Especial No.122 de 2009, cuya magistrada ponente fue la Dra. Nina Pacari, dice respecto de la seguridad jurídica:

Que es entendida como la certeza que tiene el individuo que su situación jurídica no será modificada más que por procedimientos regulares establecidos previamente. La seguridad jurídica es la condición esencial del Estado de derecho, lo que significa certeza y respeto de las actuaciones de las instituciones que conforman el Estado y de la aplicación de las normas pertinentes, es una garantía dada al individuo por el Estado de que su persona, sus bienes y su derecho, no será violentado, y que si esto llegará a producirse le será asegurado por el Estado la protección y su reparación.

El mayor desconocimiento que se puede efectuar a la seguridad jurídica, se produce y se exhibe cuando se atenta contra la estabilidad, lo que va contra la confianza que tiene el ciudadano en todo el ordenamiento jurídico vigente de su país bajo el cual es regido y el cual en letras busca proyectar seguridad jurídica. Para el establecer un mejor proceder este Acuerdo Ministerial motivo de controversia en el presente estudio, se debe partir de afianzarse en la idea de que la seguridad jurídica, es un derecho colectivo, en tanto que no se circunscribe a un solo sector o a una clase social determinada, si no que su amplitud abarca a toda a la sociedad y a cada uno de los 
ciudadanos miembros de esta, sin considerar que sean personas naturales o jurídicas y si se trata de estas últimas sean públicas o privadas, nacionales o extranjeras.

En conclusión, la forma de proceder del Acuerdo Ministerial no es la más idónea, se debería considerar no efectuar las clausuras ante la sospecha del cometimiento de una infracción y sin un proceso administrativo previo, lo cual da la posibilidad de considerar que de este proceso el presunto infractor podría ser inocente y con ello se evitaría para este sujeto el pago injustamente asignado para el levantamiento de los sellos de clausura.

Para ir finalizando es un requerimiento no obviar la mención del derecho a la defensa, derecho fundamental de una persona física o jurídica a ejercer su defensa contra los cargos que se le imputen con la seguridad de que le serán aplicadas las garantías de igualdad e independencia. Bien indica Montero Aroca en su estudio del principio de contradicción o audiencia como un principio común aplicable a todo tipo de procesos en cuanto al derecho de defensa refiere que:

Con todos estos antecedentes y con realidad del problema puntualizado, nos permite mantenernos en que existen transgresiones a los derechos y principios constitucionales, como el debido proceso, seguridad jurídica y el derecho a la defensa; en cuanto se evidencia las limitaciones de los propietarios de los establecimientos ya señalados para que de forma dialéctica puedan alegar y justificar procesalmente el reconocimiento de sus derechos e intereses.

Este estudio realizado busca exponer la forma en que afecta en el problema planteado y desarrollado, buscando así una mejor forma de precautelar los derechos de los propietarios o administradores de los centros catalogados y regidos en el acuerdo ministerial. El reconocimiento de los problemas en la forma de operar la administración de justicia es de carácter imperativo que sean expuestos para recurrir al examen de la problemática procesal existente y la vulneración de principios y derechos fundamentales. 
A continuación, se presenta la figura 1 que pretende establecer los aspectos que debió considerar el acuerdo ministerial 0069 Por cuanto recurrir a una reforma y a una unificación del texto de cuerpos legales es totalmente viable, debido a que no responden a las necesidades procesales actuales que buscan el ver realizado el ideal de una correcta administración de justicia en pro de los de derechos.

Seguridad Juridica

y derecho a la

defensa

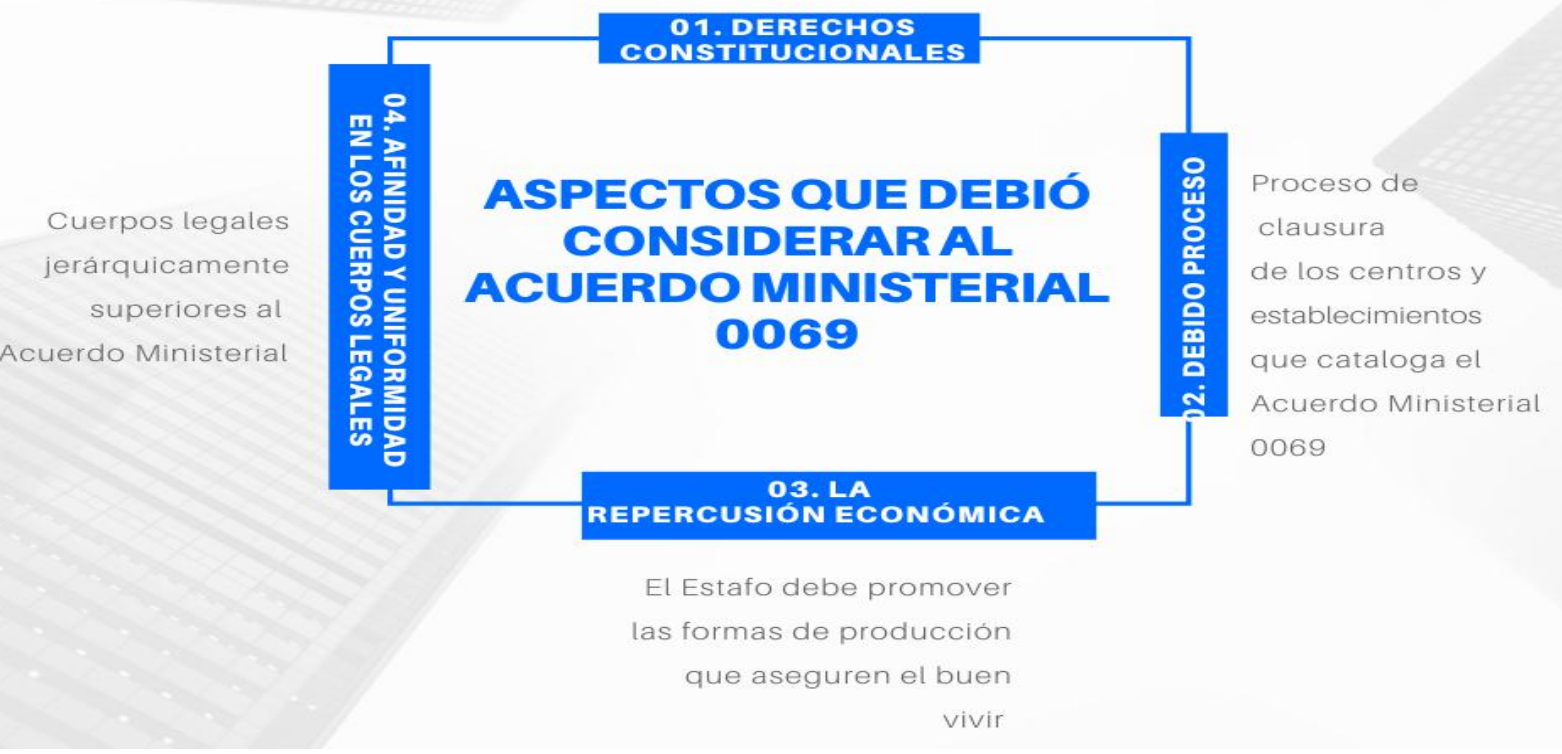

Figura 1 Consideraciones propuestas.

\section{METODOLOGÍA}

La presente investigación utilizó el enfoque cuantitativo mediante los métodos: Inductivo-deductivo, que ayudó para analizar la información teórica. Histórico - Lógico para levantar la información con el fin de conocer la situación de las variables y Analítico - sintético, que se pudo analizar algunas situaciones que afectan de manera directa a la problemática planteada. 
La aplicación de todos estos métodos permitió analizar teorías, leyes, procedimientos judiciales, jurisprudencias, bibliografías, como parte de la población de estudio, generándose mediante el análisis documental jurídico, la construcción de aportes reflexivos teóricos en el campo del derecho constitucional (Espinoza, Erazo, Ormaza y Narváez, 2020).

\section{APORTES GENERADOS}

Considerando todo lo expuesto a lo largo del estudio y análisis de la presente investigación, se analiza para concluir lo siguiente:

El actual Acuerdo Ministerial 0069 que cataloga a los centros y establecimientos sobre los cuales es materia de su aplicación y que por ende regula a los Intendentes Generales de Policía, las y los Subintendentes de Policía y Comisarios Nacionales de Policía a nivel nacional, sus atribuciones, además de los permisos de funcionamiento, las infracciones administrativas, las sanciones administrativas entre otros aspectos relacionados a los espectáculos públicos; carece de un procedimiento que sea más afín a la realidad y necesidad de los propietarios de los establecimientos y centros que el mencionado Acuerdo cataloga; en razón que los cuerpos legales deben responder y ser acordes a la necesidad de los gobernados de un país, dicho esto el actual Acuerdo Ministerial además de responder a estas necesidades, vulnera principios y garantías constitucionales.

Al estar la autoridad Administrativa como lo son los Intendentes Generales de Policía, las y los Subintendentes de Policía y Comisarios Nacionales de Policía sujetos a la observancia del debido proceso por mandato constitucional, en sus acciones o decisiones como autoridad; y en relación con la forma de proceder de los mismo por mandato del Acuerdo Ministerial 0069 se constata que se incurre en una violación al debido proceso causado por la acción que realizan al colocar los sellos de clausura en los establecimientos que cataloga el Acuerdo Ministerial, punto central del debate en la presente investigación; con ello como consecuencia se afecta aspectos de derechos 
tales como el derecho a la defensa, seguridad jurídica en cuanto a respetar el derecho al debido proceso y la tutela judicial efectiva, aspectos jurídicos sumamente importantes en los propietarios y administradores de los establecimientos en cuestión.

Es así que la situación actual de la actividad económica de los propietarios de los centros o establecimientos mencionados es gravemente afectada por la forma de proceder y resolver sobre el cometimiento de infracciones administrativas, que señala el Acuerdo Ministerial 0069, dejando así, espacios para el cometimiento de una vulneración de derechos y garantías constitucionales por parte de las autoridades administrativas y además daños económicamente significativos. Este proceso se puede indicar que es ambiguo en cuanto al contenido de clausura de los centros o establecimientos enmarcados en las siete categorías establecidas, sin embargo, es recientemente expedido el Acuerdo Ministerial al que se ha hecho mención y que no ha sufrido ningún cambio, con ello se mantienen actualmente discrepancias con la Constitución de la República, por cuanto es tarea del poder legislativo realizar una revisión y modificación de dicho acuerdo.

Dado que, si es posible mediante una reforma de dicho acuerdo para establecer un procedimiento más acorde al debido proceso, a la seguridad jurídica y al derecho a la defensa; en cuanto a la aplicación del acuerdo Ministerial 0069 en relación a las infracciones administrativas de los centros y establecimientos que él mismo Acuerdo clasifica, en donde la modificación principal sea que la colocación de los sellos de clausura a estos establecimientos sea después de un procedimiento y de una resolución administrativa, siempre y cuando se demostró el cometimiento de la infracción administrativa.

Finalmente se puede concluir con el convencimiento de la necesidad de reformar el acuerdo para se establezca una mejor aplicación de este acuerdo y más a fin los cuerpo legales jerárquicamente superiores dado que adicionalmente a los motivos expuestos es necesario que se mantenga una uniformidad en los cuerpos legales; especialmente con respecto a las atribuciones que el Código Orgánico Administrativo 
señala para los Intendentes Generales de Policía, las y los Subintendentes de Policía y Comisarios Nacionales de Policía dado que la atribución de clausurar estos locales mencionados no figura de manera expresa dentro las responsabilidades de estos en el Acuerdo Ministerial 0069.

\section{REFERENCIAS CONSULTADAS}

1. Asamblea Constitucional. (2019). Acuerdo Ministerial 0069. Quito.

2. Asamblea Constitucional. (2017). Código Orgánico Administrativo. Quito.

3. Asamblea Constitucional. (2009). Ley Orgánica de Garantías Jurisdiccionales. Quito.

4. Asamblea Constitucional. (2009). Código Orgánico de la Función Judicial. Quito.

5. Asamblea Constitucional. (2008). Constitución de la República del Ecuador. Montecristi.

6. Bermúdez, J. (1998). Elementos para Definir las Sanciones Administrativas. Revista Derecho Número especial. Chile

7. Cabanellas, G. (1976). Diccionario Jurídico (sexta edición ed., Vol. 1). Buenos Aires, Argentina: Editorial Heliasta.

8. Conferencia Especializada Interamericana. (1969). Pacto Internacional de Derechos Humanos. San José.

9. Caso No. 0481-08-EP, (Corte Constitucional. Ecuador. Sentencia No. 028-09SEP-CC,) de 08 de octubre de 2009.

10. Casos Nos. 0092-09-EP Y No. 0519-09-EP, (Corte Constitucional. Ecuador. Sentencia No. 16- SEP-CC, 29 de abril del 2010).

11. Cordero, E. (2012). El Derecho Administrativo Sancionador Y Su Relación Con El Derecho Penal. Revista de Derecho Valdivia (vol. XXV, núm. 2). Valdivia, Chile.

12. Couture, E. (1978). Vocabulario Jurídico. Buenos Aires, Argentina: Editorial La Palma. 
13. Cowin, E. (1987). La Constitución de los Estados Unidos y si Significado Actual. Buenos Aires: Editorial Fraterna.

14. Cueva, L. (2013). El debido proceso (segunda edición). Ecuador: Ediciones Cueva Carrión.

15. Espinoza Campoverde, K. A., Erazo Álvarez, J. C., Ormaza Ávila, D. A., \& Narváez Zurita, C. I. (2020). Maternidad subrogada desde la perspectiva constitucional en el Ecuador. Iustitia Socialis, 559.

16. Granda Torres, G., \& Herrera Abrahan, C. (2019). Análisis de los tipos penales y su importancia para determinar responsabilidad penal. IUSTITIA SOCIALIS, 4(7), 220-232. doi:http://dx.doi.org/10.35381/racji.v4i7.443

17. Hart, H. (1963). El concepto de Derecho". Buenos Aires: Editorial Abeledo-Perrot.

18. Jaramillo, H. (2014). La Justicia Constitucional las Acciones de Protección. Loja, Ecuador: Offset Grafimundo.

19. Montero, A. (2010). Derecho Jurisdiccional, Parte General. Valencia, España: Editorial Tirant lo Blanch.

20. Moreno, J. (2012). Procedimiento y Proceso Administrativo Práctico. Madrid, España: Editorial La Ley.

21. Suay, J. (1989). Sanciones administrativas. Revista española de derecho administrativo N.68. Bolonia: Publicaciones del Real Colegio de España.

22.Zavala, J. (2002). El debido proceso Penal. Guayaquil, Ecuador: Editorial Edino.

23. Sentencia No. 0368-2009-RA, (Corte Constitucional. 2009).

(C2020 por los autores. Este artículo es de acceso abierto y distribuido según los términos y condiciones de la licencia Creative Commons Atribución-NoComercial-Compartirlgual 4.0 Internacional (CC BY-NC-SA 4.0)

(https://creativecommons.org/licenses/by-nc-sa/4.0/). 